\title{
Excretory-secretory product of newly excysted metacercariae of Paragonimus westermani directly induces eosinophil apoptosis
}

\author{
Myeong-Heon SHIN* \\ Department of Parasitology and Institute of Medical Science, College of Medicine, \\ Ewha Womans University, Seoul 158-056, Korea
}

\begin{abstract}
Eosinophils are important effector cells in host defense against parasites. Excretory-secretory product (ESP) produced by helminthic worms plays important roles in the uptake of nutrients, migration in the host tissue, and in immune modulation. However, little is known about the ability of the ESP to directly trigger eosinophil apoptosis. This study investigated whether the ESP of newly excysted metacercariae of Paragonimus westermani could induce apoptosis in human eosinophils. Apoptosis was assayed by staining the cells with FITC-annexin V, and the cells were analyzed by flow cytometry. It was found that the ESP of newly excysted metacercariae of $P$. westermani induced a direct time- and concentration-dependent increase in the rate of constitutive apoptosis in mature human eosinophils. Eosinophil apoptosis was first apparent $3 \mathrm{hr}$ after treatment with the ESP and continued to increase after $6 \mathrm{hr}$ of incubation with respect to the cells cultured in the absence of the ESP. While only $2.8 \%$ of the eosinophils incubated in the medium for $3 \mathrm{hr}$ were apoptotic, $7.6 \%, 10.9 \%$ and $22.6 \%$ of the eosinophils treated with 10,30 and $100 \mu \mathrm{g} / \mathrm{ml}$ ESP were apoptotic, respectively. This result suggests that the ESP of newly excysted metacercariae of $P$. westermani directly induce eosinophil apoptosis, which may be important for the survival of the parasites and the reduction of eosinophilic inflammation in vivo.
\end{abstract}

Key words: Paragonimus westermani, eosinophil, apoptosis

\section{INTRODUCTION}

Eosinophils have a vital role in the pathogenesis of a number of disease states, with infiltration of eosinophils in the tissue and the blood eosinophilia being associated with helminthic parasite infection, asthma, and

- Received 7 January 2000, accepted after revision 24 February 2000.

- This study was supported by the grant No. 97-81 from the Ewha Womans University Promotion Fund (1997).

*Correspondence (e-mail: mhshin@mm.ewha. ac.kr) atopic allergy (Wardlaw et al., 1995). One major step in determining the number of eosinophils found in the blood and the tissue is to find the balance between the cell production and cell death (Simon and Blaser, 1995). Cytokines such as IL-3, IL-5 and granulocyte-macrophage-CSF (GM-CSF), or IFN- $\gamma$, have been shown to prolong the rate of survival of eosinophils by inhibiting apoptosis in vitro (Rothenberg et al., 1986; Owen et al., 1987; Valerius et al., 1990; Yamaguchi et al., 1991). Increased expression of some of these cytokines by inflammatory cells, especially by $\mathrm{T}$ lymphocytes, has been reported in patients with parasitic infections (Mahanty et al., 1993) 
or allergic diseases (Robinson et al., 1992). In contrast, ligation of the Fas receptor or CD69 and the treatment with glucocorticoids accelerate eosinophil cell death, resulting in fewer tissue eosinophils (Tsuyuki et al., 1995; Walsh et al., 1996; Woolley et al., 1996). Therefore, apoptosis of eosinophils may provide a crucial mechanism for the maintenance of homeostasis or the limitation of inflammation.

Much is known about the induction of apoptosis in host cells by intracellular pathogens such as viruses, bacteria, and parasites. For example, apoptosis of the human colon epithelial cells has been observed after mucosal infection with HIV-1 (Clayton et al., 1992) and invasive enteric pathogen such as Salmonella or enteroinvasive Escherichia coli (Kim et al., 1998). Infection of biliary epithelial cell lines or intestinal cell lines with Cryptosporidium parvum leads to host cell death (Chen et al., 1998; Ojcius et al., 1999). However, little is known about the induction of apoptosis in eosinophils by secretory component of helminthic worms.

Paragonimus westermani is a trematode fluke that causes pulmonary or extrapulmonary paragonimiasis in humans. Ingested metacercariae of $P$. westermani migrate from the intestine to the lungs in humans. During the infection, excysted larvae release excretory-secretory product (ESP) that contains a large quantity of proteolytic enzymes, which play important roles in migration in the host tissue and immune modulation. For example, proteolytic enzymes of ESP produced by newly excysted larvae of $P$. westermani are capable of degrading collagen, fibronectin, and myosin in vitro (Chung et al., 1995). In addition, purified protease from the ESP of the larvae suppresses a number of immune responses and induce immune tolerance to specific antigens in vivo (Hamajima et al., 1994). However, it is not known about the role of ESP of newly excysted larvae of $P$. westermani participating in the survival and the death of human eosinophils. Therefore, this study was aimed to find out the direct effect of ESP secreted by newly excysted larvae of $P$. westermani on apoptosis of mature human eosinophils.

\section{MATERIALS AND METHODS}

\section{Preparation of excretory-secretory products (ESP) of newly excysted metacercariae of Paragonimus wester- mani}

Metacercariae of $P$. westermani were collected from naturally infected freshwater crayfish, Cambaroides similis, from an endemic area in Korea. The soft tissue of crayfish, crushed in a mortar, was emulsified in physiological saline, filtered through a mesh screen, and the sediment was examined under a dissecting microscope. ESP of $P$. westermani metacercariae was prepared by transferring 5,000 newly excysted metacercariae into $5 \mathrm{ml}$ physiological saline, and incubated at $37^{\circ} \mathrm{C}$ in a $5 \% \mathrm{CO}_{2}$ incubator for $12 \mathrm{hr}$. The incubation medium was dialyzed against distilled water and centrifuged at $12,000 \mathrm{rpm}$ for $30 \mathrm{~min}$. The resulting supernatant was lyophilized and diluted with an appropriate medium to the desired concentration immediately before use. The concentration of ESP were measured using the bicinchoninic acid protein assay kit (Pierce, IL, USA)

\section{Isolation of peripheral blood eosino- phils}

Eosinophils were isolated by the method described previously (Hansel et al., 1991) with minor modifications, using immunomagnetic beads (Miltenyi Biotech, Germany) and the magnetic cell separation system (Miltenyi Biotech) from peripheral blood of healthy individuals. Briefly, venous blood anticoagulated with $50 \mathrm{U} / \mathrm{ml}$ heparin was diluted with PIPES buffer ( $25 \mathrm{mM}$ PIPES, $50 \mathrm{mM} \mathrm{NaCl}$, $5 \mathrm{mM} \mathrm{KCl}, 25 \mathrm{mM} \mathrm{NaOH}, 5.4 \mathrm{mM}$ glucose, $\mathrm{pH}$ 7.4) at a 1:1 ratio. Diluted blood was overlaid on isotonic Histopaque solution (density, $1.083 \mathrm{~g} / \mathrm{ml}$ ) (Sigma) and centrifuged at $1,000 \mathrm{~g}$ for $30 \mathrm{~min}$ at $4{ }^{\circ} \mathrm{C}$. The supernatant and mononuclear cells at the interface were carefully removed, and erythrocytes in sediment were lysed by two cycles of hypotonic water lysis. Isolated granulocytes were washed with PIPES buffer with $1 \%$ fetal calf serum (FCS) (Gibco, USA). An approximately equal 
volume of anti-human CD16-conjugated magnetic beads (Mitenyi Biotech) was added to the cell pellet. After $30 \mathrm{~min}$ of incubation on ice, cells were loaded onto the separation column positioned in the strong magnetic field of the magnetic activated cell sorter. Cells were eluted with PIPES buffer containing 1\% FCS. The purity of eosinophils counted by Randolph's stain was consistently greater than 95\%. Purified eosinophils were washed and resuspended in the reaction medium.

\section{Eosinophil survival assay}

Freshly purified eosinophils were suspended at $1 \times 10^{6}$ cells $/ \mathrm{ml}$ in RPMI supplemented with $50 \mu \mathrm{g} / \mathrm{ml}$ gentamycin and $10 \% \mathrm{FCS}$. One hundred microliter aliquots of the cell suspension were mixed with $100 \mu \mathrm{l}$ of three different concentrations of $\operatorname{ESP}(20,60,200$ $\mu \mathrm{g} / \mathrm{ml}$ ), or with the medium alone in 96-well flat bottom tissue culture plates and incubated for 3 or $6 \mathrm{hr}$ at $37^{\circ} \mathrm{C}$ and $5 \% \mathrm{CO}_{2}$. After incubation, the entire cell suspension was transferred to $12 \times 75-\mathrm{mm}$ polystyrene round bottom tubes. An equal volume $(200 \mu \mathrm{l})$ of propidium iodide solution was added to the cell suspension to provide a final concentration of $0.5 \mu \mathrm{g} / \mathrm{ml}$ propidium iodide. Cell counting was performed by flow cytometry (FACScan, Becton Dickinson, USA). At least 10,000 cells were analyzed from each sample, and viable cells were calculated as the percentage of intact cells not stained with propidium iodide divided by the total number of intact cells.

\section{Assay for apoptosis}

FITC-conjugated annexin V, which binds to phosphatidylserine, and 7-aminoactinomycin (7-AAD, $20 \mu \mathrm{g} / \mathrm{ml}$ ) were added to $10^{5}$ cells, after which cells were incubated for $15 \mathrm{~min}$ at room temperature in the dark, and the cells were analyzed by flow cytometry. Early apoptotic cells were stained with annexin-V alone, whereas necrotic and late apoptotic cells were stained with both annexin $\mathrm{V}$ and 7AAD.

\section{Statistical analysis}

Data are presented as mean \pm SEM from the number of experiments indicated. Statistical significance of the differences between two groups was assessed with paired Student's $t$ test.

\section{RESULTS}

Eosinophils from normal donors were treated with three different concentrations (10, $30,100 \mu \mathrm{g} / \mathrm{ml}$ ) of excretory-secretory product (ESP) of newly excysted metacercariae of $P$. westermani, and the cell viability was assessed by staining the cells with propidium iodide. Fig. 1. shows the viability of eosinophils incubated with the ESP for 3 or $6 \mathrm{hr}$. The percentage of viable cells in eosinophils treated with $10 \mu \mathrm{g} / \mathrm{ml}$ ESP was $96.9 \pm 1.17 \%$ after 3 $\mathrm{hr}$ and $85.8 \pm 9.76 \%$ after $6 \mathrm{hr}$ of incubation compared to $99.1 \pm 0.09 \%$ and $98.9 \pm 0.16 \%$, respectively, for the non-treated controls. The percentage of viable cells in eosinophils treated with $30 \mu \mathrm{g} / \mathrm{ml} \mathrm{ESP}$ was $88.0 \pm 4.97 \%$ after 3 $\mathrm{hr}$ and $79.1 \pm 2.95 \%$ after $6 \mathrm{hr}$ of incubation. In addition, the percentage of viable cells in eosinophils treated with $100 \mu \mathrm{g} / \mathrm{ml}$ ESP was $65.4 \pm 2.45 \%$ after $3 \mathrm{hr}$ and $33.8 \pm 13.05 \%$ after $6 \mathrm{hr}$ of incubation. These results show that the ESP of newly excysted metacercariae

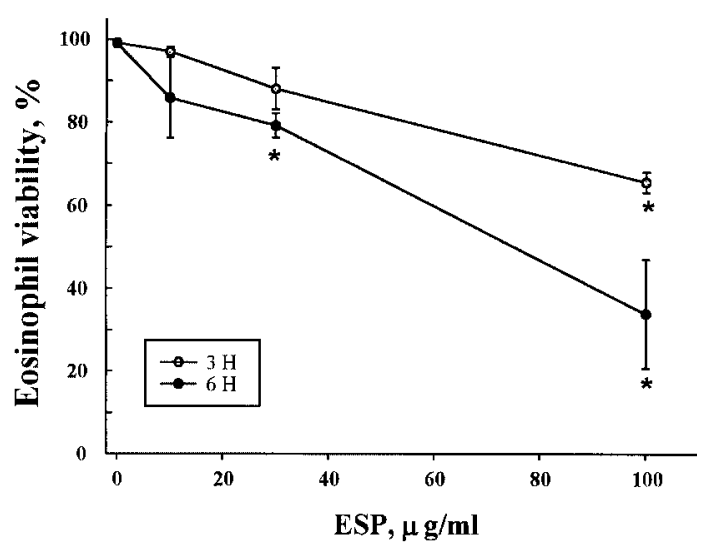

Fig. 1. Viability of eosinophils incubated with soluble excretory-secretory products (ESP) of newly excysted metacercariae of Paragonimus westermani. Eosinophils were incubated for 3 or $6 \mathrm{hr}$ with serial dilutions of ESP. After incubation, cell viability was determined by staining cells with PI and using flow cytometry. Results are presented as mean \pm SEM from three separate experiments. *Statistically significant difference $(P<0.05)$ compared with cells cultured in the absence of ESP. 

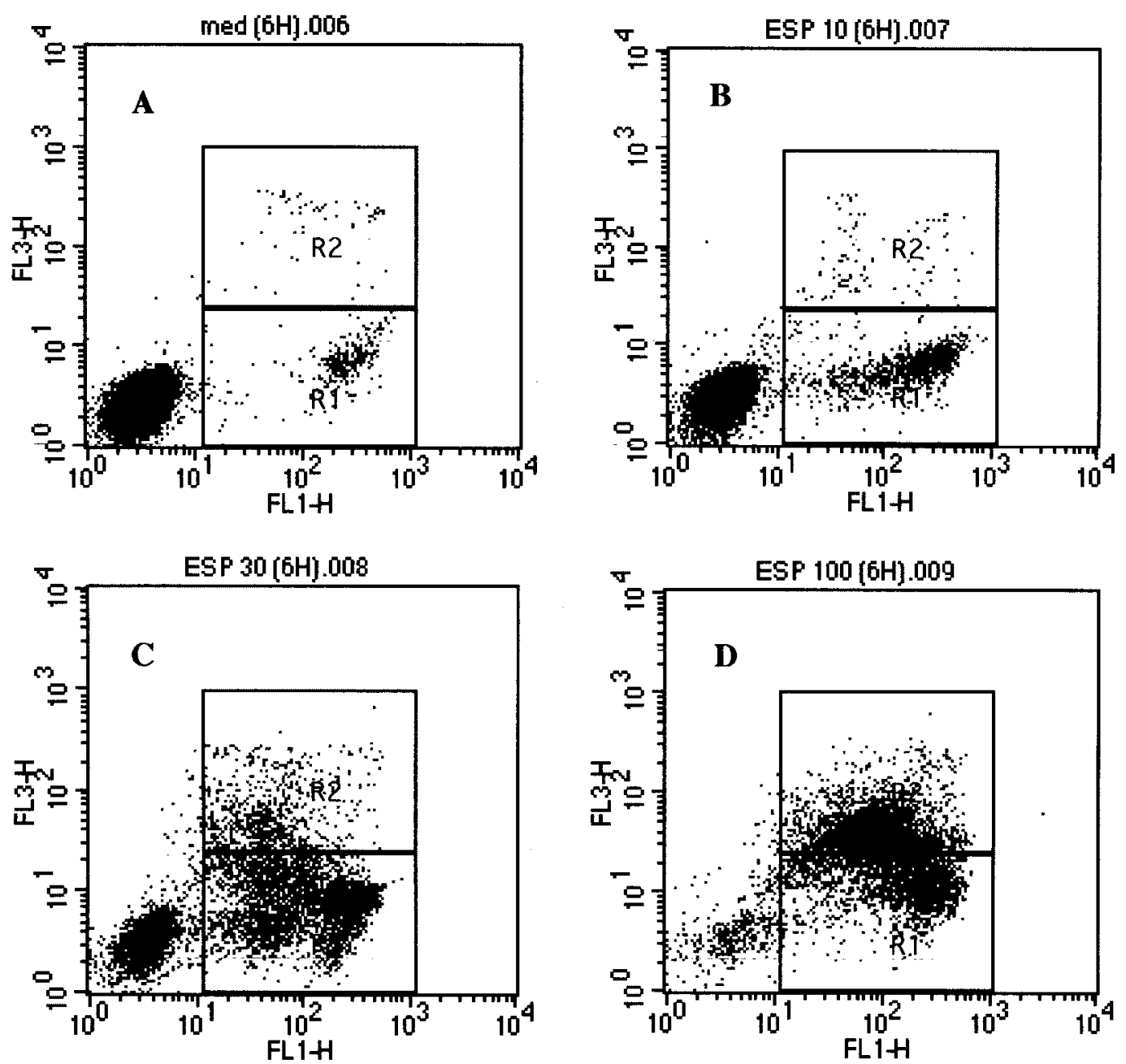

Fig. 2. Flow cytometry analysis of apoptosis of eosinophils treated with soluble ESP of Paragonimus westermani newly excysted metacercariae. Eosinophils in 96 well plates were incubated without ESP as controls (A), or were incubated with ESP [10 $\mu \mathrm{g} / \mathrm{ml}$ (B), $30 \mu \mathrm{g} / \mathrm{ml}$ (C), or $100 \mu \mathrm{g} / \mathrm{ml}$ (D)] for $6 \mathrm{hr}$ at $37^{\circ} \mathrm{C}$. After incubation, eosinophils were stained with FITC-annexin V and 7-AAD, and analyzed by flow cytometry. FL1-H and FL3-H indicates fluorescence intensity of FITC-annexin V and 7-AAD, respectively. Data are from a representative experiment. Early apoptotic cells have increased annexin V, but not 7AAD staining as indicated by the area marked R1. Necrotic and late apoptotic cells stained with both annexin V and 7-AAD as indicated by the area R2 (control, $1.0 \%$ of cells; ESP $10 \mu \mathrm{g} / \mathrm{ml}, 3.1 \%$ of cells; ESP $30 \mu \mathrm{g} / \mathrm{ml}, 15.1 \%$ of cells; ESP $100 \mu \mathrm{g} / \mathrm{ml}, 53.3 \%$ of cells). Quantitative data for R1 obtained from three independent experiments are presented in Table 1.

of $P$. westermani leads to eosinophil death in a dose- and time-dependent manner.

To determine whether eosinophil death induced by the ESP was due to programmed cell death (apoptosis), eosinophils were stained with FITC-annexin V to detect externalization of phosphatidylserine to the outer leaflet of the cell membrane. As shown in Fig. 2 and Table 1 , the ESP caused a rapid induction of eosinophil apoptosis, which was both concentration and time dependent. After 3 and $6 \mathrm{hr}$ in the wells, in which eosinophils were cultured in the medium alone, most cells were nonapoptotic. In contrast, when eosinophils were incubated with 10,30 , and $100 \mu \mathrm{g} / \mathrm{ml}$ ESP for $3 \mathrm{hr}, 7.6 \%, 10.9 \%$, and $22.6 \%$ of eosinophils were apoptotic (Table 1). The rate of eosinophil apoptosis induced by the ESP 
Table 1. Apoptosis of eosinophils in response to treatment with excretory-secretory products (ESP) of newly excysted metacercariae of Paragonimus westermania)

\begin{tabular}{lcccccc}
\hline \hline & \multicolumn{2}{c}{ Apoptotic cells (\%) } & & \multicolumn{2}{c}{ Ratio treated/control } \\
\cline { 2 - 3 } \cline { 6 - 6 } & $3 \mathrm{hr}$ & $6 \mathrm{hr}$ & & $3 \mathrm{hr}$ & $6 \mathrm{hr}$ \\
\hline Control & $\left.2.8 \pm 0.73^{\mathrm{b}}\right)$ & $3.2 \pm 0.99$ & & 1 & 1 \\
$\mathrm{ESP} 10 \mu \mathrm{g} / \mathrm{ml}$ & $7.6 \pm 2.43$ & $28.9 \pm 15.30$ & & 2.7 & 9.0 \\
ESP $30 \mu \mathrm{g} / \mathrm{ml}$ & $10.9 \pm 3.25$ & $\left.46.6 \pm 6.01^{\mathrm{c}}\right)$ & & 3.8 & 14.6 \\
ESP $100 \mu \mathrm{g} / \mathrm{ml}$ & $22.6 \pm 3.21^{\mathrm{c})}$ & $22.5 \pm 5.71$ & & 8.1 & 7.0 \\
\hline
\end{tabular}

a)Eosinophils were incubated with soluble ESP at the concentrations indicated for 3 or $6 \mathrm{hr}$ at $37^{\circ} \mathrm{C}$. Apoptosis was assayed by annexin $\mathrm{V}$ and $7-\mathrm{AAD}$ staining. b) Data are presented as mean \pm SEM from three or four independent experiments. $\left.{ }^{c}\right)$ Statistically significant difference $(P<0.05)$ compared with cells cultured in the absence of ESP.

(100 $\mu \mathrm{g} / \mathrm{ml})$ significantly increased compared to the cells incubated with medium alone. When eosinophils were incubated with 10,30 , and $100 \mu \mathrm{g} / \mathrm{ml} \mathrm{ESP} \mathrm{for} 6 \mathrm{hr}, 28.9 \%, 46.6 \%$, and $22.5 \%$ of eosinophils were found to be apoptotic (Table 1). Interestingly, the rate of apoptosis induced by $100 \mu \mathrm{g} / \mathrm{ml} \mathrm{ESP} \mathrm{at} 6 \mathrm{hr}$ of incubation were less than that induced by 10 or $30 \mu \mathrm{g} / \mathrm{ml}$ ESP.

\section{DISCUSSION}

This study shows that the excretorysecretory product (ESP) of newly excysted metacercariae of $P$. westermani induces a direct time- and concentration-dependent increase in the rate of constitutive apoptosis in mature human eosinophils. The ESP decreased the level of eosinophil survival in a dose- and time-dependent manner. This reduction of cell viability induced by the ESP was due to apoptosis. When annexin $\mathrm{V}$ staining of eosinophils was used to recognize early apoptotic cells by redistribution of their membrane phospholipid, it was found that the number of apoptotic eosinophils at 3 and $6 \mathrm{hr}$ were significantly $(P<0.05)$ higher in the culture medium with the ESP compared to the cells incubated with culture medium alone. For example, while only $2.8 \%$ of eosinophils incubated in the medium for $3 \mathrm{hr}$ were stained with annexin V, 22.6\% of eosinophils incubated with $100 \mu \mathrm{g} / \mathrm{ml}$ ESP were apoptotic at the same incubation time. Interestingly, when eosinophils were cultured in the presence of $100 \mu \mathrm{g} / \mathrm{ml} \mathrm{ESP}$ for $6 \mathrm{hr}$, the percentage of apoptotic cells stained with annexin $\mathrm{V}$ was less than that induced by a lower concentration (10 or $30 \mu \mathrm{g} / \mathrm{ml}$ ). This result indicates that apoptosis induced by the ESP is considered to be a rapid event at the highest concentration tested $(100 \mu \mathrm{g} / \mathrm{ml})$ and suggests that the mechanism of ESP on eosinophil survival is not due to a simple cytotoxicity. In addition, it would be interesting to investigate the effect of ESP on the survival of eosinophils cultured with cytokines such as IL-3, IL-5, and GM-CSF.

This study also suggests that ESP of newly excysted metacercariae of $P$. westermani retain a biologically active component inducing eosinophil apoptosis. Although it is currently being investigated in the laboratory, there seems to be a plausible explanation with respect to apoptosis induced by biologically active components. It is well known that 27 and $28 \mathrm{KDa}$ cysteine proteases are shown to be the main components of metacercarial ESP (Chung et al., 1995), and protease-activated receptors (PARs) for serine protease, such as thrombin, are functionally expressed in the human cells including neutrophils and platelets (Kahn et al., 1999). Therefore, the possibility is that the cysteine protease may specifically induce eosinophil apoptosis, although PARs for cysteine protease in eosinophils are not yet identified. This hypothesis is supported by my preliminary data that the purified $27 \mathrm{KDa}$ cysteine protease from the ESP can directly induce eosinophil apoptosis (unpublished data).

Regulation of apoptosis in host cells is a 
recently recognized mechanism of virulence for several intracellular parasites. Infection with Toxoplasma gondii inhibits the target cell apoptosis in response to several stimuli, including Fas-dependent and -independent pathways (Nash et al., 1998). However, a more virulent strain of $T$. gondii has been found to induce macrophage apoptosis (Hisaeda et al., 1997). In addition, glycoinositolphospholipid (GIPL) ceramide from pathogenic protozoan Trypanosoma cruzi induces marked apoptosis in macrophage in the presence of IFN- $\gamma$ (Freirede-Lima et al., 1998). Bone marrow-derived macrophages infected with Leishmania donovani are resistant to apoptosis induction by the removal of macrophage (M)-CSF (Moore and Matlsahewski, 1994). This increased survival of macrophage could also be induced by leishmanial lipophosphoglycan and was attributed to autocrine secretion of TNF- $\alpha$ and GM-CSF by infected macrophage. Taken together, these studies suggest that distinct intracellular parasites control host cell apoptosis to survive within infected cells and to spread infection. Therefore, this study also suggests that the ESP of newly excysted metacercariae of $P$. westermani is also involved in the control of eosinophil apoptosis, which reduces eosinophil inflammation and renders the infection relatively asymptomatic. Therefore, it would be important to examine whether the ESP of newly excysted metacercariae of $P$. westermani could attenuate eosinophilic-associated inflammation in vivo.

\section{ACKNOWLEDGEMENTS}

The author would like to thank Mr. YongMoo Won, Department of Parasitology, College of Medicine, Ewha Womans University for his help in collecting freshwater crayfish and isolating $P$. westermani metacercariae from the crayfish.

\section{REFERENCES}

Chen XM, Levine SA, Tietz P, et al. (1998) Cryptosporidium parvum is cytopathic for cultured human biliary epithelia via an apoptotic mechanism. Hepatology 28: 906913.
Chung YB, Kong Y, Joo IJ, Cho SY, Kang SY (1995) Excystment of Paragonimus westermani metacercariae by endogenous cysteine protease. J Parasitol 81: 137-142.

Clayton F, Reka S, Cronin WJ, Torlakovic E, Sigal SH, Kotler DP (1992) Rectal mucosal pathology varies with human immunodeficiency virus antigen content and disease stage. Gastroenterology 103: 919-933.

Freire-de-Lima CG, Nunes MP, Corte-Real S, et al. (1998) Proapoptotic activity of a Trypanosoma cruzi ceramide-containing glycolipid turned on in host macrophages by IFN- $\gamma . J$ Immunol 161: 4909-4916.

Hamajima F, Yamamoto M, Tsura S, et al. (1994) Immunosuppression by neutral thiol protease from parasitic helminth larvae in mice. Parasite Immunol 16: 261-273.

Hansel TT, de Vries IJM, Iff T, et al. (1991) An improved immunomagnetic procedure for the isolation of highly purified human blood eosinophils. J Immunol Methods 145: 105110.

Hisaeda H, Sakai T, Ishikawa H, et al. (1997) Heat shock protein 65 induced by $\gamma \delta$ T cells prevents apoptosis of macrophages and contributes to host defense in mice infected with Toxoplasma gondii. J Immunol 159: 2375-2381.

Kahn ML, Nayumi NM, Shapiro MJ, Ishihara H, Coughlin SR (1999) Protease-activated receptors 1 and 4 mediate activation of human platelets by thrombin. $J$ Clin Invest 103: 879-887.

Kim JM, Eckmann L, Savidge TC, Lowe DC, Witthoft T, Kagnoff MF (1998) Apoptosis of human intestinal epithelial cells after bacterial invasion. J Clin Invest 102: 18151823.

Mahanty S, King CL, Kumaraswami V, et al. (1993) IL-4- and IL-5-secreting lymphocyte populations are preferentially stimulated by parasite-derived antigens in human tissue invasive nematode infections. J Immunol 151: 3704-3711.

Moore KJ, Matlashewski G (1994) Intracellular infection by Leishmania donovani inhibits macrophage apoptosis. J Immunol 152: 29302937.

Nash PB, Purner MB, Leon RP, Clarke P, Duke RC, Curiel TJ (1998) Toxoplasma gondiiinfected cells are resistant to multiple inducers of apoptosis. $J$ Immunol 160: 18241830. 
Ojcius DM, Perfettini JL, Bonnin A, Laurent F (1999) Caspase-dependent apoptosis during infection with Cryptosporidium parvum. Microbes Infect 1: 1163-1168.

Owen WF, Rothenberg ME, Silberstein DS, et al. (1987) Regulation of human eosinophil viability, density, and function by granulocyte-macrophage colony-stimulating factor in the presence of $3 \mathrm{~T} 3$ fibroblast. J Exp Med 166: 129-141.

Robinson DS, Hamid Q, Ying S, et al. (1992) Predominant TH2-like bronchoalveolar Tlymphocyte population in atopic asthma. New Engl J Med 326: 298-304.

Rothenberg ME, Owen WF, Silberstein DS, et al. (1986) Human eosinophils have prolonged survival, enhanced functional properties, and become hypodense when exposed to human IL-3. J Clin Invest 81: 1986-1992.

Simon HU, Blaser K (1995) Inhibition of programmed eosinophil death: A key pathogenic event for eosinophilia? Immunol Today 16: 53-55.

Tsuyuki S, Bertrand C, Erard F, et al. (1995) Activation of the Fas receptor on lung eosinophils leads to apoptosis and the resolution of eosinophilic inflammation of the airways. J Clin Invest 96: 2924-2931.

Valerius T, Repp R, Kalden JR, Platzer E (1990) Effects of IFN on human eosinophils in comparison with other cytokines: a novel class of eosinophil activators with delayed onset of action. J Immunol 145: 2950-2958.

Walsh GM, Williamson ML, Symon FA, Willars GB, Waldlaw AJ (1996) Ligation of CD69 induces apoptosis and cell death in human eosinophils cultured with granulocytes / macrophage colony-stimulating factor. Blood 87: 2815-2821.

Wardlaw AJ, Moqbel R, Kay AB (1995) Eosinophils: biology and roles in disease. Adv Immunol 60: 151-266.

Woolley KL, Gibson PG, Carty K, Wilson AJ, Twaddell SH, Woolley MJ (1996) Eosinophil apoptosis and the resolution of airway inflammation in asthma. Am J Resp Crit Care Med 154: 237-243.

Yamaguchi Y, Suda T, Ohta S, Tominaga K, Miura Y, Kasahara T (1991) Analysis of the survival of mature human eosinophils: interleukin-5 prevents apoptosis in mature human eosinophils. Blood 78: 2542-2547. 